\title{
Thermodynamic parameters depend on temperature with the influence of doping ratio of the crystal structure metals in extended $\mathrm{X}$-Ray absorption fine structure
}

\author{
Duc Nguyen Ba ${ }^{1, a}$, Tho Quang Vu ${ }^{2}$, Hiep Trinh Phi ${ }^{3}$, Quynh Lam Nguyen Thi ${ }^{4}$ \\ 1, 2, 3 Faculty of Physics, Tan Trao University, Vietnam \\ ${ }^{4}$ University of Science - Ha Noi National University \\ aEmail:ducnb@daihoctantrao.edu.vn
}

\section{Article info}

Recieved:

$02 / 11 / 2018$

Accepted:

$10 / 12 / 2018$

Keywords:

Brackpoint; cumulants;

doping ratio; parameter; thermodynamic.

\begin{abstract}
The effects of the doping ratio and temperature on the cumulants and thermodynamic parameters of crystal structure metals and their alloys was investigated using the anharmonic correlated Einstein model, in extended X-ray absorption fine structure (EXAFS) spectra. We derived analytical expressions for the EXAFS cumulants, correlated Einstein frequency, Einstein temperature, and effective spring constant. We have considered parameters of the effective Morse potential and the Debye-Waller factor depend on temperature and the effects of the doping ratio of face-centered-cubic (fcc) crystals of copper $(\mathrm{Cu}-\mathrm{Cu})$, silver (Ag-Ag), and hexagonal-close-packed (hcp) crystal of zinc ( $\mathrm{Zn}-\mathrm{Zn}$ ), and their alloys of $\mathrm{Cu}-\mathrm{Ag}$ and $\mathrm{Cu}-\mathrm{Zn}$. The derived anharmonic effective potential includes the contributions of all the nearest neighbors of the absorbing and scattering atoms. This accounts for three-dimensional interactions and the parameters of the Morse potential, to describe single-pair atomic interactions. The numerical results of the EXAFS cumulants, thermodynamic parameters, and anharmonic effective potential agree reasonably with experiments and other theories.
\end{abstract}

\section{Introduction}

Extended X-ray absorption fine structure spectra has developed into a powerful probe of atomic structures and the thermal effects of substances $[1,5,8-15]$. The dependence of the thermodynamic properties and cumulants of the lattice crystals of a substance on the temperature with influence doping ratio (DR) was studied using this technique. The thermodynamic parameters and the EXAFS cumulants for pure cubic crystals, such as crystals of copper $(\mathrm{Cu})$ doped with silver (Ag) (Cu-Ag), which depend on DR and temperature, have been derived using the anharmonic correlated Einstein model (ACEM) in EXAFS theory $[6,8,10]$. However, the effect of the doping ratio and temperature on the thermodynamic parameters and cumulants of the EXAFS for copper doped with zinc
( $\mathrm{Cu}-\mathrm{Zn})$, copper doped with silver at a level not above $50 \%$, is yet to be determined.

In this study, we use anharmonic effective potential from EXAFS theory $[8,10,15]$ to formulate thermodynamic parameters, such as the effective force constants, expressions of cumulants, thermal expansion coefficient, correlated Einstein frequency, and correlated Einstein temperature, these parameters are contained in the anharmonic EXAFS spectra. The $\mathrm{Cu}-\mathrm{Ag}$ and $\mathrm{Cu}-\mathrm{Zn}$ doped crystals contain pure $\mathrm{Cu}, \mathrm{Ag}$, and $\mathrm{Zn}$ atoms. The $\mathrm{Ag}$ and $\mathrm{Zn}$ atoms are referred to as the substitute atoms and the $\mathrm{Cu}$ atoms are referred to as the host atoms. The expression $\mathrm{CuAg} 72$ indicates a ratio of $72 \% \mathrm{Ag}$ and $28 \% \mathrm{Cu}$ atoms in the alloy, and $\mathrm{CuZn} 45$ indicates $45 \%$ $\mathrm{Zn}$ and $55 \% \mathrm{Cu}$ in the alloy. Numerical calculations have been conducted for doped crystals to determine 
the thermodynamic effects and how they depend on the DR and temperature of the crystals. The results of the calculations are in good agreement with experimental values and those of other studies [2-11,13,16,17].

\section{Formalism}

The anharmonic EXAFS function, including the anharmonic contributions of atomic vibration, is often expressed as $[1,10,15]$

$\chi(k)=\frac{S_{0}^{2} N}{k R^{2}} F(k) \exp \left(-\frac{2 R}{\lambda(k)}\right) \operatorname{Im}\left(e^{i \theta(k)} \exp \left(2 i k r_{0}+\sum_{n} \frac{(2 i k)^{n}}{n !} \sigma^{(n)}(T)\right)\right)$,

where $R=<r>$ with $r$ is the instantaneous bond length between absorbing and scattering atoms at temperature $T$ and $r_{0}$ is its equilibrium value, $S_{0}^{2}$ is the intrinsic loss factor due to many electron effects, $N$ is the atomic number of a shell, $F(k)$ is the atomic backscattering amplitude, $k$ and $\lambda$ are the wave number and mean free path of the photoelectron, and $\Phi(k)$ is the total phase shift of the photoelectron. In the ACEM [10,15], interaction between absorbing and scattering atoms with contributions from atomic neighbors is characterized by an effective potential. To describe the asymmetric components of the interactive potential, the cumulants $\sigma^{(n)}(n=1,2,3,4, \ldots)$ are used. To determine the cumulants, it is necessary to specify the interatomic potential and force constant. Consider a high-order expanded anharmonic interatomic effective potential, expanded up to fourth order, namely

$$
V(x) \approx \frac{1}{2} k_{e f f} x^{2}+k_{3 e f f} x^{3}+k_{4 e f f} x^{4}+\ldots
$$

where $k_{\text {eff }}$ is an effective spring constant that includes the total contribution of the neighboring atoms, and $k_{3 e f f}$ and $k_{4 e f f}$ are effective anharmonicity parameters that specify the asymmetry of the anharmonic effective potential, $x=r-r_{0}$ is net deviation. The effective potential, given by Eq. 2, is defined based on the assumption of an orderly centerof-mass frame for a single-bond pair of an absorber and a bacskcatterer $[7,10,15]$. For monatomic crystals, the masses of the absorber and backscatterer are the same, so the effective potential is given by

$$
V_{E}(x)=V(x)+\sum_{i=0,1} \sum_{j \neq i} V\left(\frac{\mu}{M_{i}} x \hat{\mathrm{R}}_{01} \cdot \hat{\mathrm{R}}_{\mathrm{ij}}\right),
$$

where $\mathrm{V}(\mathrm{x})$ includes only absorber and backscatter atoms, $i$ is the sum of the absorber $(i=1)$ and backscatter $(i=2)$ atoms, and $j$ is the sum of all their near neighbors, excluding the absorber and backscatterer themselves, whose contributions are described by the term $\mathrm{V}(\mathrm{x}), \mu$ is the reduced atomic mass, $\hat{R}$ is the unit bond-length vector. Therefore, this effective pair potential describes not only the pair interaction of the absorber and backscatter atoms but also how their near-neighbor atoms affect such interactions. This is the difference between the effective potential of this study and the single-pair potential [7] and single-bond potential [1], which consider only each pair of immediate neighboring atoms, i.e., only $\mathrm{V}(\mathrm{x})$, without the remaining terms on the right-hand side of Eq. 3. The atomic vibration is calculated based on a quantum statistical procedure with an approximate quasi-harmonic vibration, in which the Hamiltonian of the system is written as a harmonic term with respect to the equilibrium at a given temperature, plus an anharmonic perturbation:

$$
\begin{aligned}
& H=\frac{P^{2}}{2 \mu}+V_{E}(\chi)=H_{0}+V_{E}(a)+\delta V_{E}(y), \\
& H_{0}=\frac{P^{2}}{2 \mu}+\frac{1}{2} k_{\text {eff }} y^{2},
\end{aligned}
$$

with $y=x-a, a(T)=\langle x\rangle$, and $\langle y\rangle=0$, where $y$ is the deviation from the equilibrium value of $x$ at absolute temperature $T$ and $a$ is the net thermal expansion. The potential interaction between each pair of atoms in the single bond can be expressed by the anharmonic Morse potential and expanding to fourth order, and considering orderly doped crystals, we assign the host atom the indicator 1 and the substitute atom the indicator 2 , and have 
$V_{E}(x)=D_{12}\left(e^{-2 \alpha_{12} x}-2 e^{-\alpha_{12} x}\right) \approx D_{12}\left(-1+\alpha_{12}^{2} x^{2}-\alpha_{12}^{3} x^{3}+\frac{7}{12} \alpha_{12}^{4} x^{4} \ldots\right)$,

where D12 is the dissociation energy, $V\left(r_{0}\right)=-D$, and $\alpha_{12}$ describes the width of the potential. For simplicity, we approximate the parameters of the Morse potential in Eq. 5 at a certain temperature by

$D_{12}=c_{1} D_{1}+c_{2} D_{2}, \quad \alpha_{12}=\sqrt{\left(D_{1} \alpha_{1}^{2}+D_{2} \alpha_{2}^{2}\right) /\left(D_{1}+D_{2}\right)}$,

where $c_{1}, c_{2}$ are the DR (\%) of the alloy and $c_{1}=1-c_{2}$. We calculate $\left(\hat{\mathrm{R}}_{01} \cdot \hat{\mathrm{R}}_{\mathrm{ij}}\right)$ in Eq. 3 for lattice face-centred cubic (fcc) crystals, substitute Eq. 5 with $x=y+a$ into Eq. 3 , and calculate the sums in the second term of Eq. 3 with the reduced mass $\mu$ of the doped metals. Comparison of the results with the factors of Eq. 2 and Eq. 5 yields the coefficients $k_{\text {eff }}$, $k_{3 e f f}$ and $k_{4 e f f}$ of the anharmonic effective potential, in terms of the parameters of the Morse potential, namely

$$
k_{\text {eff }}=5 D_{12} \alpha_{12}^{2}, \quad k_{3 e f f}=\frac{5 D_{12} \alpha_{12}^{3}}{4}, k_{4 e f f}=\frac{7 D_{12} \alpha_{12}^{4}}{12} .
$$

To derive analytical formulas for the cumulants, we use perturbation theory [15]. The atomic vibration is quantized as phonons, considering the phonon-phonon interactions to account for anharmonicity effects, with correlated Einstein frequency and correlated Einstein temperature:

$$
\omega_{E}=\sqrt{k_{\text {eff }} / \mu_{12}}, \quad \theta_{E}=\hbar \omega_{E} / k_{B},
$$

Where $k_{B}$ is the Boltzmann constant, we obtain the cumulants up to third order:

$$
\begin{aligned}
& \sigma^{(1)}=\frac{3 \hbar \omega_{E}}{40 \mathrm{D}_{12} \alpha_{12}} \frac{\left(1+\exp \left(-\theta_{E} / T\right)\right)}{\left(1-\exp \left(-\theta_{E} / T\right)\right)} \\
& \sigma^{(2)}=\frac{\hbar \omega_{E}}{10 D_{12} \alpha_{12}^{2}} \frac{\left(1+\exp \left(-\theta_{E} / T\right)\right)}{\left(1-\exp \left(-\theta_{E} / T\right)\right)} \\
& \sigma^{(3)}=\frac{3 \hbar^{2} \omega_{E}^{2}}{200 D_{12}^{2} \alpha_{12}^{3}} \frac{\left(1+10 \exp \left(-\theta_{E} / T\right)+\left(\exp \left(-\theta_{E} / T\right)\right)^{2}\right)}{\left(1-\exp \left(-\theta_{E} / T\right)\right)^{2}},
\end{aligned}
$$

dependence of the linear thermal expansion coefficient on the absolute temperature $\mathrm{T}$ with efects the DR of the doped metals:

$$
\alpha_{T}=\frac{3 k_{B}}{20 \mathrm{D}_{12} \alpha_{12} r} \frac{\exp \left(-\frac{\theta_{E}}{\mathrm{~T}}\right)\left[\ln \left(\exp \left(-\frac{\theta_{E}}{\mathrm{~T}}\right)\right)\right]^{2}}{\left(1-\exp \left(-\frac{\theta_{E}}{\mathrm{~T}}\right)\right)^{2}},
$$

and the anharmonic factor as

$$
\begin{gathered}
\beta=\frac{9 \eta k_{B} T}{16 \mathrm{D}_{12}}\left[1+\frac{3 k_{B} T}{8 D_{12} R \alpha_{12}}\left(1+\frac{3 k_{B} T}{8 D_{12} R \alpha_{12}}\right)\right], \\
\eta=\frac{2 \exp \left(-\frac{\theta_{E}}{T}\right)}{1+\exp \left(-\frac{\theta_{E}}{T}\right)} .
\end{gathered}
$$

Factor $\beta$ is proportional to the temperature and inversely proportional to the shell radius, thus reflecting a similar anharmonicity property obtained in experimental catalysis research [2] if $R$ is considered as the particle radius. Eqs. 9-13 describe how the cumulants, thermal expasion coefficient, and anharmonic factor depend on the absolute temperature $T$ and effects of the reduced mass $\mu_{12}$ of the doped metals. Therefore, the first cumulant $\sigma^{(1)}$ or net thermal expansion, the second cumulant $\sigma^{(2)}$ also known as the Debye-Waller factor (DWF) or meansquare relative displacement (MSRD), and the third cumulant $\sigma^{(3)}$ describe the asymmetric interactive potential in the XAFS.

\section{Results and discussion}

The calculated and experimental [4] parameter values of the Morse potential, $D_{12}$ and $\alpha_{12}$, for the pure metals and their alloy crystals are given in Table I.

TABLE I. Parameter values of Morse potential for pure metals and their alloy crystals

\begin{tabular}{ccccc}
\hline Crystal & $\begin{array}{c}D_{12}(\mathrm{eV}) \\
\text { (Present theory) }\end{array}$ & $\begin{array}{c}D_{12}(\mathrm{eV}) \\
\left(\text { Exp. }^{4}\right)\end{array}$ & $\begin{array}{c}\alpha_{12}\left(\AA^{-1}\right) \\
(\text { Present theory) }\end{array}$ & $\begin{array}{c}\alpha_{12}\left(\AA^{-1}\right) \\
\left(\text { Exp. }^{4}\right)\end{array}$ \\
\hline $\mathrm{Cu}-\mathrm{Cu}$ & 0.3429 & 0.3528 & 1.3588 & 1.4072 \\
$\mathrm{Ag}-\mathrm{Ag}$ & 0.3323 & 0.3253 & 1.3690 & 1.3535 \\
$\mathrm{Zn-Zn}$ & 0.1698 & 0.1804 & 1.7054 & 1.7000 \\
$\mathrm{CuAg} 72$ & 0.3381 & - & 1.3634 & - \\
$\mathrm{CuZn45}$ & 0.2650 & - & 1.4672 & -
\end{tabular}


Substituting the parameters $D_{12}$ and $\alpha_{12}$ from Table I into Eq. 7, with Boltzmann's constant $k_{B}=8.617 \times 10^{-5} \mathrm{eV} \AA^{-1}$ and Planck's constant $\hbar=6.5822 \times 10^{-16} \mathrm{eV} . \mathrm{s}$, we calculate the values of the anharmonic effective potential in terms of the parameters of the Morse potential, Einstein frequency $\omega_{E}$, and Einstein temperature $\theta_{E}$ of crystals, as given in Table II.

TABLE II. Anharmonic effective parameter values

\begin{tabular}{|c|c|c|c|c|c|c|c|c|}
\hline Crystal & $\begin{array}{l}k_{e j}\left(\mathrm{eVA}^{-2}\right) \\
\text { (Present) }\end{array}$ & $\begin{array}{l}k_{e f f}\left(\mathrm{eVA}^{-2}\right) \\
(\text { Exp.,17) }\end{array}$ & $\begin{array}{l}k_{3 f f}\left(\mathrm{eVA}^{-3}\right) \\
\text { (Present) }\end{array}$ & $\begin{array}{c}k_{3 f f f}\left(\mathrm{eVA}^{-5}\right) \\
\left(\operatorname{Exp}^{4}\right)\end{array}$ & $\begin{array}{l}k_{+e f}\left(\mathrm{eVA}^{-1}\right) \\
\text { (Present) }\end{array}$ & $\begin{array}{c}k_{t+f}\left(\mathrm{eVA}^{-1}\right) \\
\left(\operatorname{Exp}^{4}\right)\end{array}$ & $\begin{array}{c}\omega_{E} \\
\left(10^{13} \mathrm{~Hz}\right)\end{array}$ & $\theta_{E}(K)$ \\
\hline $\mathrm{Cu}-\mathrm{Cu}$ & 3.1655 & 3.4931 & 1.0753 & 1.2289 & 0.6646 & 0.8070 & 3.0889 & 236 \\
\hline $\mathrm{Ag}-\mathrm{Ag}$ & 3.1139 & 2.9797 & 1.0657 & 1.0083 & 0.6809 & 0.6368 & 3.3933 & 176 \\
\hline $\mathrm{Zn}-\mathrm{Zn}$ & 2.4692 & 2.4348 & 1.4889 & 1.0348 & 0.8378 & 0.8209 & 2.6868 & 206 \\
\hline $\mathrm{CuAg} 7$ & 3.1423 & - & 1.0710 & - & 0.6814 & - & 2.6874 & 207 \\
\hline $\mathrm{CuZn} 45$ & 2.8522 & - & 1.0462 & - & 0.7163 & - & 2.9161 & 223 \\
\hline
\end{tabular}

Substituting the values of the thermodynamic parameters from Tables I and II into Eqs. 2, 9-13, we obtain expressions for the anharmonic effective potential $V(x)$, which depends on $\mathrm{T}$, and the cumulants $\sigma^{(n)}(n)$, which depend on the DR and T.

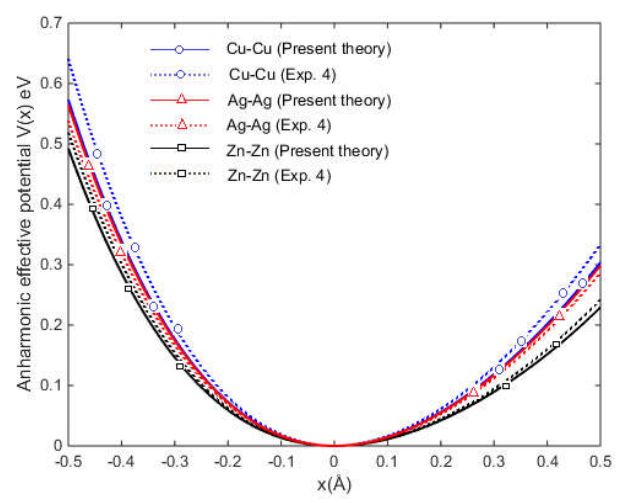

FIG. 1. Comparison between present theory and experimental values of anharmonic effective Morse potential

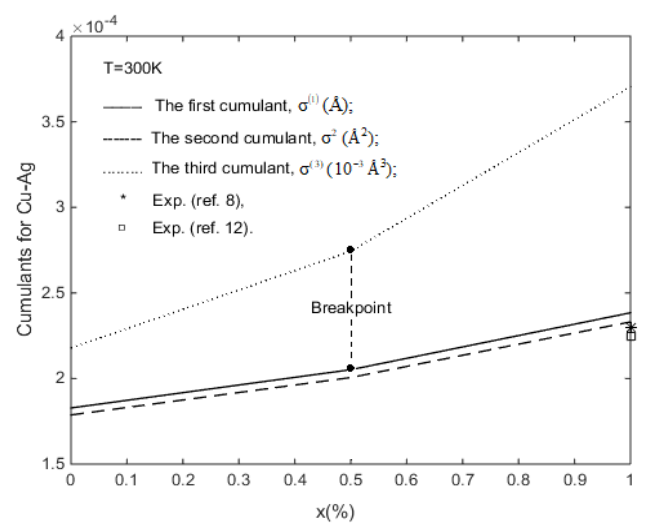

FIG. 2. Dependence of cumulants on doping ratio (DR) CuAg50.

In Figure 1, we compare the calculated anharmonic effective Morse potential (solid lines) and experimental data (dotted lines) from H.Ö. Pamuk and T.Halicioğlu [4], for $\mathrm{Cu}$ (blue curve with symbol $\circ$ ), $\mathrm{Ag}$ (red curve with symbol $\Delta$ ), and Zn (black curve with symbol $\square$ ). The calculated curves of the Morse potential align closely with the experimental curves, indicating that the calculated data for the coefficients $k$ eff, $k 3 e f f$, and $k 4 e f f$, from the ACEM, are in good agreement with the measured experimental values. Figure 2 shows how the first three calculated cumulants depend on the DR at a given temperature $(300 \mathrm{~K})$, for the compound $\mathrm{Cu}-\mathrm{Ag}$. The graphs of $\sigma^{(1)}(T), \sigma^{(2)}(T)$, and $\sigma^{(3)}(T)$ illustrate that for DRs of zero to below $50 \%$ and from over $50 \%$ to $100 \%$, the cumulant values are proportional to the DR. For the second cumulant or $\mathrm{DWF}$, at the point where the ratio of $\mathrm{Ag}$ atom decreases to $0 \%$ and the ratio of $\mathrm{Cu}$ atoms increases to $100 \%$ (symbols *, $\square$ ), the calculated value is in good agreement with experimental values, at $300 \mathrm{~K}[8,12]$. However, there are breakpoints in the lines at the 0.5 point on the $\mathrm{x}$ axis, meaning that we do not have ordered atoms at a DR of 50\%. Thus, $\mathrm{Cu}-\mathrm{Ag}$ alloys do not form an ordered phase at a molar composition of 1:1, i.e., the $\mathrm{CuAg} 50$ alloy does not exist. This result is in agreement with the findings of J. C. Kraut and W. B. Stern [6].

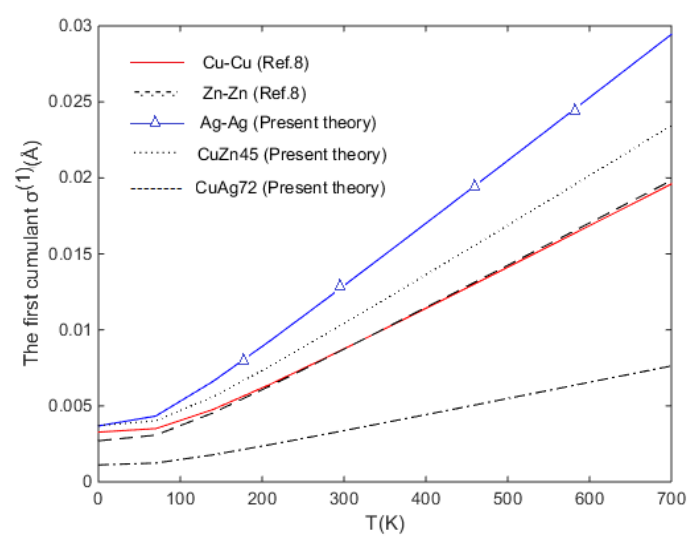

FIG. 3. Temperature dependence of the first cumulant for $\mathrm{Cu}, \mathrm{Ag}, \mathrm{Zn}$, and their alloys, with the effect of $\mathrm{DR}$. 


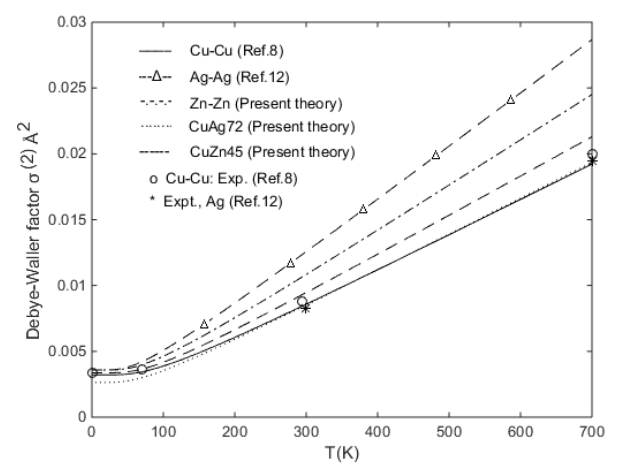

FIG. 4. Temperature dependence of the second cumulant (Debye-Waller factor) for $\mathrm{Cu}, \mathrm{Ag}, \mathrm{Zn}$, and their alloys, with the effect of $D R$.

Figure 3 shows the temperature dependence of the calculated first cumulant, or net thermal expansion $\sigma^{(1)}$ for $\mathrm{Cu}, \mathrm{Ag}, \mathrm{CuAg} 72$ (the alloy with $28 \% \mathrm{Cu}$ atoms and $72 \% \mathrm{Ag}$ atoms, referred to as CuSil or UNS P07720 [16]), and CuZn45 (the alloy with 55\% Cu atoms and $45 \% \mathrm{Zn}$ atoms referred to as the brass [17], a yellow alloy of copper and zinc). Figure 4 illustrates the temperature dependence of the calculated second cumulant or DWF $\sigma^{(2)}$, for $\mathrm{Cu}-\mathrm{Cu}, \mathrm{Ag}-\mathrm{Ag}, \mathrm{Zn}-\mathrm{Zn}$, and their alloys $\mathrm{CuAg} 72$ and $\mathrm{CuNi45}$, and comparison with the experimental values $[8,12]$. There good agreement at low temperatures and small differences at high temperatures, and the measured results between the results for $\mathrm{CuAg} 72$ and $\mathrm{CuNi} 45$ with $\mathrm{Cu}$ values are reasonable. Calculated values for the first cumulant (Fig. 3), and the DWF (Fig. 4) with the effects of the DRs, are proportional to the temperature at high temperatures. At low temperatures there are very small, and contain zero-point contributions, which are a result of an asymmetry of the atomic interaction potential of these crystals due to anharmonicity. Figure 5 shows the temperature dependence of the calculated third cumulant $\sigma^{(3)}$, for $\mathrm{Cu}-\mathrm{Cu}, \mathrm{Ag}-\mathrm{Ag}, \mathrm{Zn}-\mathrm{Zn}$, and their alloys $\mathrm{CuAg} 72$ and $\mathrm{CuZn} 45$. The calculated results are in good agreement with the experimental values $[8,12]$. The curves in Figures 3, 4, and 5 for $\mathrm{CuZn} 45$ and $\mathrm{CuAg} 72$ are very similar to the $\mathrm{Cu}-\mathrm{Cu}$ curve, illustrating the fit between theoretical and experimental results. The calculated first three cumulants contain zero-point contributions at low temperatures are in agreement with established theory. Furthermore, the calculations and graphs demonstrate that the alloys of two $\mathrm{Cu}-\mathrm{Zn}$ elements with $\mathrm{Zn}$ content less than or equal $45 \%$ enhances the durability and ductility of copper alloys, when the $\mathrm{Zn}$ content exceeds $50 \%$ in the $\mathrm{Cu}-\mathrm{Zn}$ alloy, it becomes hard and brittle. Alloy $\mathrm{CuZn} 45$ is often used as heat sinks, ducts and stamping parts because of its high viscosity [17]. Also, $\mathrm{CuAg} 72$ is an eutectic alloy, primarily used for vacuum brazing [16].

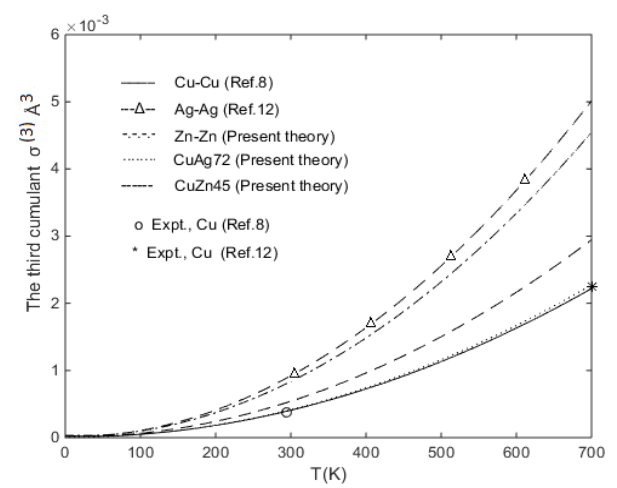

FIG. 5. Temperature dependence of the third cumulant for $\mathrm{Cu}, \mathrm{Ag}, \mathrm{Zn}$, and their alloys, with the effect of $D R$

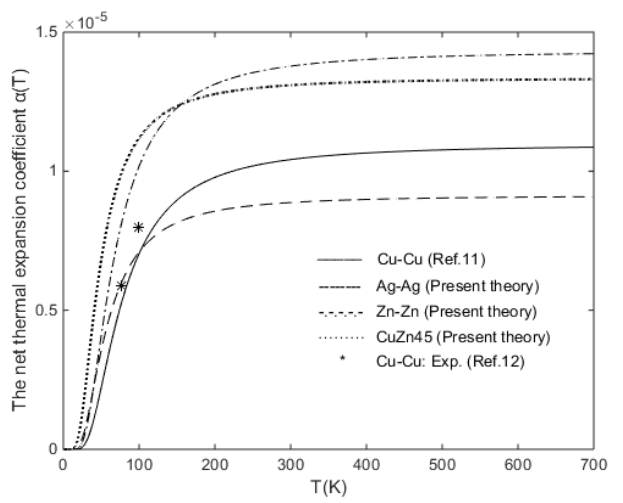

FIG. 6. Dependence of thermal expansion coefficient on temperature and effect of $D R$

Figure 6 shows how our calculated thermal expansion coefficient $\alpha_{T}$ of $\mathrm{Cu}-\mathrm{Cu}, \mathrm{Ag}-\mathrm{Ag}, \mathrm{CuAg} 72$, and $\mathrm{CuZn} 45$ depends on temperature and effects DR. With the absolute temperature $T$, our $\alpha_{T}$ have the form of the specific heat $C_{V}$, thus reflecting the fundamental principle of solid state theory that the thermal expansion results from anharmonic effects and is proportional to the specific heat $C_{V}$ [15]. Our calculated values of $\alpha_{T}$ approach the constant value $\alpha_{T}^{0}$ at high temperatures and vanish exponentially with $\theta_{E} / T$ at low temperatures, which agrees with the findings of other research [12]. 


\section{Conclusions}

A new analytical theory for calculating and evaluating the thermodynamic properties of $\mathrm{Cu}, \mathrm{Ag}$, and $\mathrm{Zn}$, taking into consideration the effects of the DRs in alloys, was developed based on quantum statistical theory with the effective anharmonic Einstein potential. The expressions for the thermodynamic parameters, effective force constant, correlated Einstein frequency and temperature, and cumulants expanded up to third order, for $\mathrm{Cu}, \mathrm{Ag}$, and $\mathrm{Zn}$ crystals and their alloys agree with all the standard properties of these quantities. The expressions used in the calculations for the orderly doped crystals have similar forms to those for pure crystals. Figs. 1-6 show the dependence of thermodynamic parameters on temperature and effects the DR for the crystals. They reflect the properties of anharmonicity in EXAFS and agree well with results obtained in previous studies. Reasonable agreement was obtained between the calculated results and experimental and other studies of $\mathrm{Cu}, \mathrm{Ag}, \mathrm{Zn}, \mathrm{CuAg} 72$, and $\mathrm{CuZn} 45$. This indicates that the method developed in this study is effective for calculating and analyzing the thermodynamic properties of doped crystals, based on the ACEM in EXAFS theory.

\section{REFERENCES}

[1] A. I. Frenkel and J. J. Rehr, Phys. Rev. B 48, 585 (1993).

[2] B. S. Clausen, L. Grabæk, H. Topsoe, L. B. Hansen, P. Stoltze, J. K. Norskǿv, and O. H. Nielsen, J. Catal. 141, 368 (1993).

[3] Duc B. N., Hung N.V., Khoa H.D., Vuong D.Q., and Tien S.T., Advances in Materials Sciences and Engineering, Vol 2018, Article ID 3263170, 9 pages doi.org/10.1155/2018/3263170 (2018).

[4] H.Ö. Pamuk and T. Halicioğlu, Phys. Stat. Sol. A 37, 695 (1976).

[5] Hung N. V., Trung N. B., and Duc B. N., J. Materials Sciences and Applications 1(3) (2015) 91.

[6] J. C. Kraut and W. B. Stern, J. Gold Bulletin 33(2) (2000) 52.

[7] J. M. Tranquada and R. Ingalls, Phys. Rev. B 28, 3520 (1997).

[8] N. V. Hung, N. B. Duc, and R. R. Frahm, J. Phys. Soc. Jpn. 72(5), 1254 (2002).
[9] N. V. Hung, T. S. Tien, N. B. Duc, and D. Q. Vuong, Modern Physics Letter B 28 (21), 1450174 (2014).

[10] N. V. Hung and J. J. Rehr, Phys. Rev. B 56 (1997) 43.

[11] N. V. Hung, C. S. Thang, N. B. Duc, D. Q. Vuong and T. S. Tien, Eur. Phys. J. B 90, 256 (2017).

[12] N. V. Hung, N. B. Duc, Proceedings of the Third International Workshop on Material Science (IWOM'S99, 1999).

[13] N. V. Hung and N. B. Duc, Commun. in Phys., 10, (2000) 15-21.

[14] N. B. Duc, V. Q. Tho, N. V. Hung, D. Q. Khoa, and H. K. Hieu, Vacuum 145, 272 (2017).

[15] N. B. Duc, H. K. Hieu, N. T. Binh, and K. C. Nguyen, X-Ray absorption fine structure: basic and applications, Sciences and Technics Publishing House, Hanoi, 2018.

[16] A. Nafi, M. Cheikh, and O. Mercier, "Identification of mechanical properties of CuSil-steel brazed structures joints: a numerical approach," Journal of Adhesion Science and Technology 27 (24), 2705 (2013), doi:10.1080/01694243.2013.805640.

[17] M. A. Laughton and D. F. Warne, Electrical Engineers Reference Book (Elsevier, ISBN: 978-07506-4637-6, 2003), pp.10. 


\title{
Các tham số nhiệt động phụ thuộc vào nhiệt độ với ảnh hưởng của tỷ lệ pha tạp đối với các kim loại có cấu trúc tinh thể trong phổ cấu trúc tinh tế hấp thụ tia $\mathrm{X}$ mở rộng
}

\author{
Nguyễn Bá Đức, Vũ Quang Thọ, Trịnh Phi Hiệp, Nguyễn Thị Lâm Quỳnh
}

\section{Thông tin bài viết}

Ngày nhận bài:

$02 / 11 / 2018$

Ngày duyệt đăng:

$10 / 12 / 2018$

\section{Tù khoá:}

Điểm gãy; cumulant; tỷ lẹ pha tạp; tham số; nhiệt động

\section{Tóm tắt}

\begin{abstract}
Ảnh hưởng của tỷ lệ pha tạp và nhiệt độ đến các cumulant và các tham số nhiệt động của kim loại có cấu trúc tinh thể và hợp kim của chúng đã được nghiên cứu bằng Mô hình Einstein tương quan phi điều hòa, trong phổ cấu trúc tinh tế hấp thụ tia $\mathrm{X}$ mở rộng (EXAFS). Chúng tôi đã xác định được các biểu thức giải tích của các cumulant phổ EXAFS, tần số tương quan Einstein, nhiệt độ Einstein và hằng số lực hiệu dụng. Chúng tôi đã xem xét các tham số thế Morse hiệu dụng và hệ số Debye-Waller phụ thuộc vào nhiệt độ với ảnh hưởng của tỷ lệ pha tạp đối với các tinh thể có cấu trúc lập phương tâm mặt (fcc) như đồng $(\mathrm{Cu}-\mathrm{Cu})$, bạc $(\mathrm{Ag}-\mathrm{Ag})$ và tinh thể có cấu trúc lục giác xếp chặt (hcp) như kẽm và hợp kim của chúng $\mathrm{Cu}-\mathrm{Ag}$ và $\mathrm{Cu}-\mathrm{Zn}$. Đã xác định thế hiệu dụng phi điều hòa bao gồm sự đóng góp của các nguyên tử hấp thụ và tán xạ lân cận gần nhất. Các phép tính toán này đã tính đến tương tác ba chiều và các tham số của thế Morse để mô tả các tương tác nguyên tử đơn cặp. Các kết quả tính số của các cumulant phổ EXAFS, các tham số nhiệt động và thế hiệu dụng phi điều hòa phù hợp với các kết quả thực nghiệm và lý thuyết khác.
\end{abstract}

